\title{
Nursing staff readiness toward advanced mobile devices utilization in nursing care in critical care units
}

\author{
Samah El Sayed Rashed ${ }^{1}$, Abeer Mohamed Seade ${ }^{2}$, Fawzia Farouk Kamel ${ }^{3}$ \\ ${ }^{1}$ Instructor of Nursing Administration, Faculty of Nursing, Benha University, ${ }^{2}$ Assistant \\ Professor of Nursing Administration, Faculty of Nursing, Cairo Univeristy, ${ }^{3}$ Lecturer of Nursing \\ Administration, Faculty of Nursing, Benha University.
}

\begin{abstract}
Background A new reality is obligated that advanced mobile devices (AMDs) adoption is recognized for advanced nursing practice. The Egyptian health organizations have little attention in AMDs adoption, thus inappropriate nursing staff readiness is a challenge of AMDs compliance and application. The purpose of the study was to assess nursing staff (head nurses and staff nurses) readiness toward AMDs utilization in nursing care in critical care units. A descriptive comparative design was used to achieve the aim of the present study. The study setting this study was conducted at Benha University Hospital. Sampling convenient sample of 261 nursing staff divided into 222 staff nurses and 39 head nurses with at least one year experience was constituted the study sample. Instruments used for data collection data of the present study was collected by using one instrument it was named; Advanced mobile devices readiness test questionnaire ; it consisted of three parts, first part contained personal characteristics of study subjects, Part II: AMDs knowledge questionnaire and Part III: AMDs readiness questionnaire. The result showed that the highest percent of head nurses had good knowledge level regarding AMDs utilization in nursing compared to more than two thirds of staff nurses and nearly half of head nurses were ready to use AMDs in nursing care compared to more than one third of staff nurses. The study concluded that there were statistically significant positive correlation between nursing staff total knowledge and total readiness regarding AMDs utilization in nursing care. The study recommended; the study recommended that; the informatics education programs should be incorporated into orientation program for new hiring and into a continuing education program schedule to enhance nurse's support, confidence as well as comfort at AMDs usage.
\end{abstract}

Key words: Advanced mobile devices- critical care units - nursing staff- readiness.

\section{Introduction:}

From a technological perspective, critical care unit's environments need greater capillarity of communication networks. Such as intercommunication support between heterogeneous devices and monitoring centers joint with providing greater computational access to patient information, using multiple communication channels. So there are many advances in technology have been made available to help nurses and clinicians perform their jobs and care for patients more efficiently and safely. Consequently, nursing today isn't the same as the past. From such inventions as tablet computers and other different types of advanced mobile devices
(AMDs) (Jelec, 2016; Sewell, 2016 \& Bala, 2017).

Advanced mobile devices are a general term for any handheld computer or smartphone. It is a mobile telecommunication device and computing system with advanced features such as medical applications, word processing, Internet access, and other computing capabilities. Its characterized by Wi-Fi or cellular access to the internet, A battery that powers the device for several hours, A physical or onscreen keyboard for entering information, Size and weight that allows it to be carried in one hand and manipulated with the other hand Touch-screen interface in almost all 


\section{Nursing staff readiness toward advanced mobile devices utilization in nursing care in critical care units}

cases, A virtual assistant, like Siri, Google Assistant, The ability to download data from the internet, including apps and books and Wireless operation (Zayim and Ozel, 2015; Keegan, et al., 2016 \& Choi et al., 2018).

Mobile technology has the potential to enhance nursing practice through nurses being able to find or check information about illness, disease or injury, view or revise procedures or care to be undertaken, or ensure correct medications are administered to patients without needing to go to the nurses' station, treatment room or locate a computer terminal to retrieve information. Also it promotes patient involvement and encourages selfmanagement, reduce error, prevent duplication, and enable correct sequencing of procedures. Moreover provide continuity of care by no longer needing to leave the patient, develop rapport with patients, strengthen the nurse-patient relationship, promote a mutuality of learning between students and patients and provide easy access to electronic health record systems (Mather and Cummings, 2015\& George et al., 2017).

In addition to, enable access to mobile technology will negate the current workaround of nurses which currently occurs, when nurses need to find or check information. In general, these point-of-care computing solutions include tablets, laptops, smartphones, mobile carts and handheld scanners. All of these mobile devices are essential to the larger category of mobile Health solutions which will change the concept of the health (Mather and Cummings, 2015; Mann et al., 2015\& Beauegard et al., 2017).

There are potential barriers to the implementation of AMDs in nursing care include, The cost of smartphones and the software, the small screen size, computer viruses including spyware, breaches of data privacy and security and difficulty with internet connections. Moreover the failure by management to grasp the potential of mobile technology and the non-inclusion of digital professionalism as part of professional identity formation, generational differences in interest and competence. Also there are End-user barriers include nurses lacking the confidence to use mobile technology out of concern they will make mistakes, lack of nursing staff comfort with technology, poor educational preparation of nurses and a lack of technical expertise and computer and computing system skills of staff (Martyn et al., 2014; Cummings et al., 2016\& Mechael et al., 2017).

Moreover there are barriers for the adoption of AMDs in nursing care which are generally resource constrained (e.g. insufficient E-Health infrastructure), due to lack of required information communication technology support, awareness among stake holders, and a drive to adopt new system or functions. Moreover, available information technology infrastructure (including a lack of data processing facilities) (Abelson, et al., 2017).

The application of modern technologies is an essential factor required for the advancement of nursing. Health care itself and continuous monitoring of patients requires using of Informationcommunication system (ICS). However, ICS is essential for efficient implementation of nursing documentation and effective providing of health care. Nursing staff play an active role in the implementation of technology in nursing practice in order to maintain control of the complex system that is implemented in health care. Systems that are based on knowledge are set to become a major component in the skills of nurses (Lavin et al., 2015). 


\section{Nursing staff readiness toward advanced mobile devices utilization in nursing care in critical care units}

Nursing staff readiness toward AMDs helps to identify additional competencies and education that are required in order to achieve efficient AMDs implementation. Implementation of AMDs within the hospital is a result of the interactions between technical skills, hospital culture, and social acceptance. So the head nurses have to change way of thinking about new technology. Implementation of new technologies may change practice. Also it is necessary to ensure that nursing staff have sufficient competencies necessary to work with these new technologies. The fact is, health needs of our populations have changed, nurses remain the foremost providers and, above it all, the coordinators of care (Cipriano, 2013\& Khan and Aldhafeeri, 2016).

\section{Significance of the study}

Healthcare and nursing education have been affected by many changes within larger global and national social, economic, political, cultural, and environmental spheres. So AMDs technology offers ways to cope with new life challenges which include increasing work load, increasing shortages of health professionals, and rising aged populations in many countries. Moreover in critical care units time and rapid of response is very critical for all patients (West, 2013).

AMDs utilization in nursing care environment stemmed from the rapid innovative technological revolution, especially in the field of telecommunication and nursing informatics. As AMDs become more users friendly, computationally powerful, and readily available. Some of these new AMDs apps are specifically targeted to assisting individuals in their own health and wellness management (Muhanna \& Abu-Al-Sha'r, 2009).

AMDs service offers opportunities in delivering timely information on health services to Health workers with relatively greater demand for this type of information. Health workers will be able to track and monitor patients' symptoms using mobile phones with text capabilities in conjunction with a central database. By creating an up todate database of health information, health workers can track infectious diseases in remote areas, coordinate medical supplies, and make better decisions based on more accurate information. In Egypt, the literature review offer little researches regarding using of AMDs, So this study aim to gain information regarding nursing staff readiness toward AMDs utilization in nursing care (Chetly, et al, 2015).

\section{Purpose of the study:}

This study aims to assess nursing staff (head nurses and staff nurses) readiness toward advanced mobile devices utilization in nursing care in critical care units.

\section{Research objectives}

1. Assess nursing staff knowledge regarding AMDs utilization in nursing care.

2. Identify nursing staff readiness towards AMDs utilization in nursing care.

3. Compare between head nurses and staff nurses knowledge and readiness toward AMDs utilization in nursing care.

4. Investigate relationship between nursing staff knowledge regarding AMDs utilization in nursing care and their readiness.

\section{Subjects \& Method:}

Design: A descriptive comparative design was used to achieve the aim of the present study. 


\section{Nursing staff readiness toward advanced mobile devices utilization in nursing care in critical care units}

Setting: The current study was conducted at Benha University Hospital(Free services hospital) in the following Critical Care Units with different specialists Intensive Care Unit (ICU), Intermediate ICU, Emergency ICU, Hepatic ICU, Coronary Care Unit (CCU), chest ICU, Cardiac ICU, Chest and Cardiac ICU, Pediatric ICU, Pediatric Incubator, Dialysis ICU (Adult \&Pediatric) and Psychiatric ICU.

Sampling: Convenient sample of 261 nursing staff who are working at previous mentioned setting, were eligible to participate in the study and with at least one year experience was constituted the study sample. They were divided into 222 staff nurses and 39 head nurses (three head nurses in each unit of CCUs distributed as following; one head nurse at the morning shift and two charge nurses; one at the evening shift and the other at the night shift).

Instruments of data collection: one instrument was used for data collection

\section{Advanced mobile devices readiness test questionnaire:}

Self-administered questionnaire was developed by the researcher based on literature review (Muhanna \& Abu-AlSha'r, 2009; Lioyd ,2011; Johansson \& Peterson 2014; Gill \& Tran, 2015; White \& Mills, 2015) aimed to examine nursing staff readiness toward AMDs utilization in nursing care. It consists of three parts as follows:

Part I: Personal data sheet: divided into three sections:

- Section1: it consisted of 9 questions about personal characteristics of nursing staff; (age, gender, marital status, department, job rank, qualification, and years of experience at current unit, previous training course in electronic nursing record)
- Section2: it consisted of 3 questions about the personal communication device (mobile phone)

- Section3: it consisted of 6 questions about using of personal communication device in clinical setting.

Part II: AMDs knowledge questionnaire: to assess nursing staff knowledge regarding AMDs utilization in nursing care. It consisted of 29 questions divided into 19 true or false and 10 multiple choice questions covering the following items: concept of AMDs in nursing care (5 questions), uses of AMDs in nursing care (10 questions), advantages of using AMDs in nursing care (8 questions) and disadvantages and barriers of using AMDs in nursing care (6 questions).Reliability of this tool: It was measured by using cronbach's Alpha test. The cronbach's Alpha test of knowledge of nursing staff regarding AMDs utilization in nursing care was 0 . 827

\section{Scoring system:}

The scoring system for nursing staff knowledge was calculated as follows; (2) score for correct and complete answer, while (1) score for correct and incomplete answer, and (0) for incorrect and don't know answer. The score of the items was summed-up and the total divided by the number of the items, giving a mean score for the part. These scores were converted into a percent score.

The total knowledge score (58 degrees) and it was considered good if the score of the total knowledge $\geq 75 \%$ ( $\geq 43.5$ degrees) while considered average if it equals $60-<75 \%$ ( from $34.8<43.5$ degrees), and considered poor if it is $<60 \%$ ( $<34.8$ degrees $)$.

\begin{tabular}{|c|c|}
\hline Score & Scoring Items \\
\hline 0 & Don't Know \\
\hline
\end{tabular}




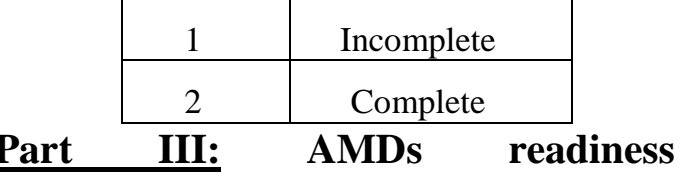
questionnaire: to assess nursing staff readiness toward AMDS utilization in nursing care. It consisted of 99 items divided into 6 dimensions distributed as follows; $1^{\text {st }}$ dimension technology readiness (23 items) divided into 4 subcategory: optimism (7 items), innovativeness ( 9 items), discomfort ( 8 items) and insecurity (9 items), $2^{\text {nd }}$ required technical skills for using AMDs (16 items), $3^{\text {rd }}$ access to information from AMDs (11 items), $4^{\text {th }}$ usefulness from using AMDs (15 items), $5^{\text {th }}$ motivation toward using AMDs (9 items) and $6^{\text {th }}$ attitude toward AMDs (15 items). Reliability of this tool: It was measured by using cronbach's Alpha test the cronbach's Alpha test of nursing staff readiness toward AMDs utilization in nursing was 0.974 .

\section{Scoring system:}

Nursing staff responses were scored on a five point Likert Scale ranged from (1) rarely to (5) always. The score was reversed for negative items. Scores of each dimension summed up and converted into percent scores. The total readiness score (495 degrees) and it was considered high if the percent score was more than $75 \%$ ( more than 371.25 degrees ), moderate if the percent score was ranged from 60 to $75 \%$ ( from 297 to 371.25 degrees), while it considered low if the percent score less than $60 \%$ (less than 297 degrees).

\begin{tabular}{|c|c|}
\hline Score & Scoring Items \\
\hline 1 & Rarely \\
\hline 2 & Often \\
\hline 3 & Sometimes \\
\hline
\end{tabular}

\begin{tabular}{|l|l|}
\hline 4 & Usually \\
\hline 5 & Always \\
\hline
\end{tabular}

Preparatory phase: This phase started from December 2016 to March 2017. It included the following:

Reviewing the national and international related literature using journals, periodicals, textbooks, internet and theoretical knowledge of the various aspects concerning the topic of the study for modifying the tools and translating the tools into Arabic language and back translation to check its accuracy.

Tools validity: face and content of study tools were validated by group of jury consisted of 5 experts from professors of different Faculty of Nursing (one assistant professor from Tanta University, two lecturers from Cairo University in nursing administration, one assistant professor from Benha University in community health nursing and The Director of the e-Learning Center and the dean of faculty of veterinary medicine from Benha University). The modifications were done based on jury opinions such as (omitted the item that gives the same meaning and modifying some words to give the right meaning for the item which did not understood clearly).

Pilot study: A pilot study was carried out in April 2017 to ascertain the clarity and applicability of the study tools. 22 staff nurses and 4 head nurses were included in the pilot study representing $10 \%$ of total study subjects. It has also served in estimating the time needed for filling the tool. It ranged between 45-60 minutes. No modification was needed. The pilot study included in the study.

\section{Ethical Considerations:.}

Before conducting the study, explanation of the nature and aim of the study have been explained to staff nurses and head nurses included in the study. All subjects were informed that 


\section{Nursing staff readiness toward advanced mobile devices utilization in nursing care in critical care units}

participation in the study is voluntary and informed consent was obtained from each participant in the study. Confidentiality of data obtained was protected by the allocation of a code number to the questionnaire sheets. Subjects were informed that the content of the study tools will be used for the research purpose only. Participants' right to withdraw from the study at any time was ascertained.

\section{Procedure:}

An official permission was issued from Dean of the Faculty of Nursing to the Director of Benha University Hospital for taking their permission to conduct the study, and seek their support. The researcher met head nurse of each department to determine suitable time to collect data from her staff

Data collection took about three months from beginning of May 2017 to end of July 2017. The researcher met nursing staff and explained the aim and the nature of the study and the method of filling questionnaire. The researcher distributed the questionnaire sheets to the participant to fill it in work times which determined in advance with head nurse of each unit according to type of work. Data was collected in three days /week in the presence of the researcher to clarify any ambiguity. The average number of sheets filled per week was ranged between 20-25.

The data were collected according to type of work and work load of each department, sometimes it was in the middle of the shift and other time before the end of the shift after an oral permission obtained from studied sample. The field work lasted for three months from the beginning of October 2015 to the end of December 2015 The average number of nurses filled the questionnaire sheets were between 4-5 nurses per day.

\section{Results}

Table (1): Shows that nearly three quarters of staff nurses $(74.8 \%)$ had age less than 30 years old with Mean \pm SD $(28.7 \pm 5.0)$, the majority of staff nurses $(91.0 \%)$ were female, more than two thirds of staff nurses $(73.0 \%)$ were married. The highest percent of them (77.0\%) had diploma in nursing, Regarding to having previous training course in electronic documentation the majority of staff nurses $(92.3 \%)$ don't have previous training course in electronic documentation.

On the other hand more than half of head nurses (51.3) had aged 31-40 years old with Mean \pm SD $(34.5 \pm 6.7)$, the majority of head nurses $(92.3 \%)$ were female, more than half of them $(53.8 \%)$ were single and more than two thirds of head nurses $(71.8 \%)$ had bachelor of nursing. Regarding to having previous training course in electronic documentation more than two thirds of head nurses $(64.1 \%)$ had previous training course in electronic documentation. Also the result shows that more than two thirds of both staff nurses and head nurses $(71.2 \%$ and $71.8 \%$ ) have from 1 to less than 10 experience years with Mean \pm SD $(8.9 \pm 5.6,8.07 \pm 3.3)$ respectively.

Table (2): Reveals that the majority of both staff nurses and head nurses (97.7\% and $100 \%)$ and $(78.8 \%$ and 87.2 $\%)$ had advanced mobile phone. Regarding to using the mobile phone for work purposes, more than two thirds of staff nurses $(64.9 \%)$ reported that they don't use the mobile phone for work purposes comparing with more than two thirds of head nurses $(61.5 \%)$ reported that they use the mobile phone for work purposes.

Table (3): Clearly show that the majority of both staff nurses and head nurses (93.2\% and 100.0\%) reported that the hospital allow personal telephone use in ICU respectively. and most of staff nurses (74.8\%) reported 


\section{Nursing staff readiness toward advanced mobile devices utilization in nursing care in critical care units}

that using of mobile phone negatively affect nursing performance comparing with more than one half of head nurses $(59.0 \%)$ reported that using of mobile phone don't negatively affect nursing performance.

In addition to the result shows that more than two thirds of staff nurses $(69.4 \%)$ reported that there is interference between mobile phone and a medical device at ICU comparing with the majority of head nurses $(94.4 \%)$. Also this table shows that more than two thirds of both staff nurses and head nurses $(65.8 \%, 69.2 \%)$ reported that the administrator should establish policy for using personal communication devices at work respectively.

Figure (1): Clearly indicates that $(54.4 \%$ and $46.2 \%)$ of both staff nurses and head nurses had positive feeling level toward using AMDs in nursing care respectively.

Figure (2): clearly indicates that the highest percent of head nurses $(75.6 \%)$ had good knowledge score regarding AMDs utilization in nursing care compared to more than two thirds of staff nurses $(62 \%)$.

Figure (3): clearly indicates that less than half of both head nurses and staff nurses $(47.2 \%$ and $44.2 \%)$ had moderate technology readiness level toward AMDs utilization in nursing care respectively.

Figure (4): Clearly shows that nearly to half of head nurses $(48.7 \%)$ had high readiness level regarding AMDs utilization in nursing care comparing with more than one third of staff nurses $(38.7 \%)$.While the minority of both head nurses and staff nurses $(10.3 \%$, $15.8 \%$ ) had low readiness level regarding AMDs utilization in nursing care respectively.

Table (4): Reveals that; there was statistically significant positive correlation between nursing staff total knowledge regarding AMDs utilization in nursing care and their total readine

Table (1): Frequency distribution of nursing staff regarding personal characteristics $\mathrm{No}=(\mathbf{2 6 1})$

\begin{tabular}{|c|c|c|c|c|c|}
\hline \multirow{2}{*}{\multicolumn{2}{|c|}{ Personal characteristics }} & \multicolumn{2}{|c|}{$\begin{array}{c}\text { Staff nurses } \\
\text { No=222 }\end{array}$} & \multicolumn{2}{|c|}{$\begin{array}{c}\text { Head nurses } \\
\text { No=39 }\end{array}$} \\
\hline & & No & $\%$ & No & $\%$ \\
\hline \multirow{3}{*}{ Age } & $<30$ & 166 & 74.8 & 14 & 35.9 \\
\hline & $31-40$ years & 51 & 23.0 & 20 & 51.3 \\
\hline & $41<50$ years & 5 & 2.2 & 5 & 12.8 \\
\hline \multicolumn{2}{|l|}{ Mean \pm SD } & \multicolumn{2}{|c|}{$28.7 \pm 5.0$} & \multicolumn{2}{|c|}{$34.5 \pm 6.7$} \\
\hline \multirow{2}{*}{ Sex } & Male & 20 & 9.0 & 3 & 7.7 \\
\hline & Female & 202 & 91.0 & 36 & 92.3 \\
\hline \multirow{3}{*}{ Marital status } & Single & 54 & 24.3 & 21 & 53.8 \\
\hline & Married & 162 & 73.0 & 18 & 46.2 \\
\hline & widow & 6 & 2.7 & 0 & 0.0 \\
\hline \multirow[t]{2}{*}{ Place of living } & Urban & 42 & 18.9 & 6 & 15.4 \\
\hline & Rural & 180 & 81.1 & 33 & 84.6 \\
\hline \multirow{3}{*}{ Qualification } & Diploma in Nursing & 41 & 18.5 & 3 & 7.7 \\
\hline & $\begin{array}{l}\text { Nursing Diploma } \\
\text { above average }\end{array}$ & 171 & 77.0 & 8 & 20.5 \\
\hline & Bachelor of Nursing & 10 & 4.5 & 28 & 71.8 \\
\hline \multirow{3}{*}{ Experience years } & $1<10$ years & 158 & 71.2 & 28 & 71.8 \\
\hline & $10<15$ years & 28 & 12.6 & 11 & 28.2 \\
\hline & $>15$ years & 36 & 16.2 & 0 & 0.0 \\
\hline \multicolumn{2}{|l|}{ Mean \pm SD } & \multicolumn{2}{|c|}{$8.9 \pm 5.6$} & \multicolumn{2}{|c|}{$8.07 \pm 3.3$} \\
\hline \multirow{2}{*}{$\begin{array}{l}\text { Having previous training course in } \\
\text { electronic documentation }\end{array}$} & Yes & 17 & 7.7 & 25 & 64.1 \\
\hline & No & 205 & 92.3 & 14 & 35.9 \\
\hline
\end{tabular}


Nursing staff readiness toward advanced mobile devices utilization in nursing care in critical care units

Table (2): Frequency distribution of nursing staff regarding personal communication device $\mathrm{No}=(\mathbf{2 6 1})$

\begin{tabular}{||l|l|l|l|l|l||}
\hline \multicolumn{2}{|c|}{ personal communication device items } & \multicolumn{2}{c|}{$\begin{array}{c}\text { Staff nurses } \\
\text { No=222 }\end{array}$} & \multicolumn{2}{c|}{$\begin{array}{c}\text { Head nurses } \\
\text { No=39 }\end{array}$} \\
\cline { 3 - 7 } \multicolumn{2}{|c|}{} & No & $\%$ & No & $\%$ \\
\hline \multirow{2}{*}{ Have mobile phone } & Yes & 217 & 97.7 & 39 & 100.0 \\
\cline { 2 - 7 } Type of mobile phone & No & 5 & 2.3 & 0 & 0.0 \\
\hline \multirow{2}{*}{$\begin{array}{l}\text { Using the mobile phone for work } \\
\text { purposes }\end{array}$} & Simple & 42 & 18.9 & 5 & 12.8 \\
\cline { 2 - 7 } & Advanced & 175 & 78.8 & 34 & 87.2 \\
\cline { 2 - 7 } & Nos & 78 & 35.1 & 24 & 61.5 \\
\hline
\end{tabular}

Table (3): Frequency distribution of nursing staff regarding using personal communication device in clinical setting $\mathrm{No}=(\mathbf{2 6 1})$

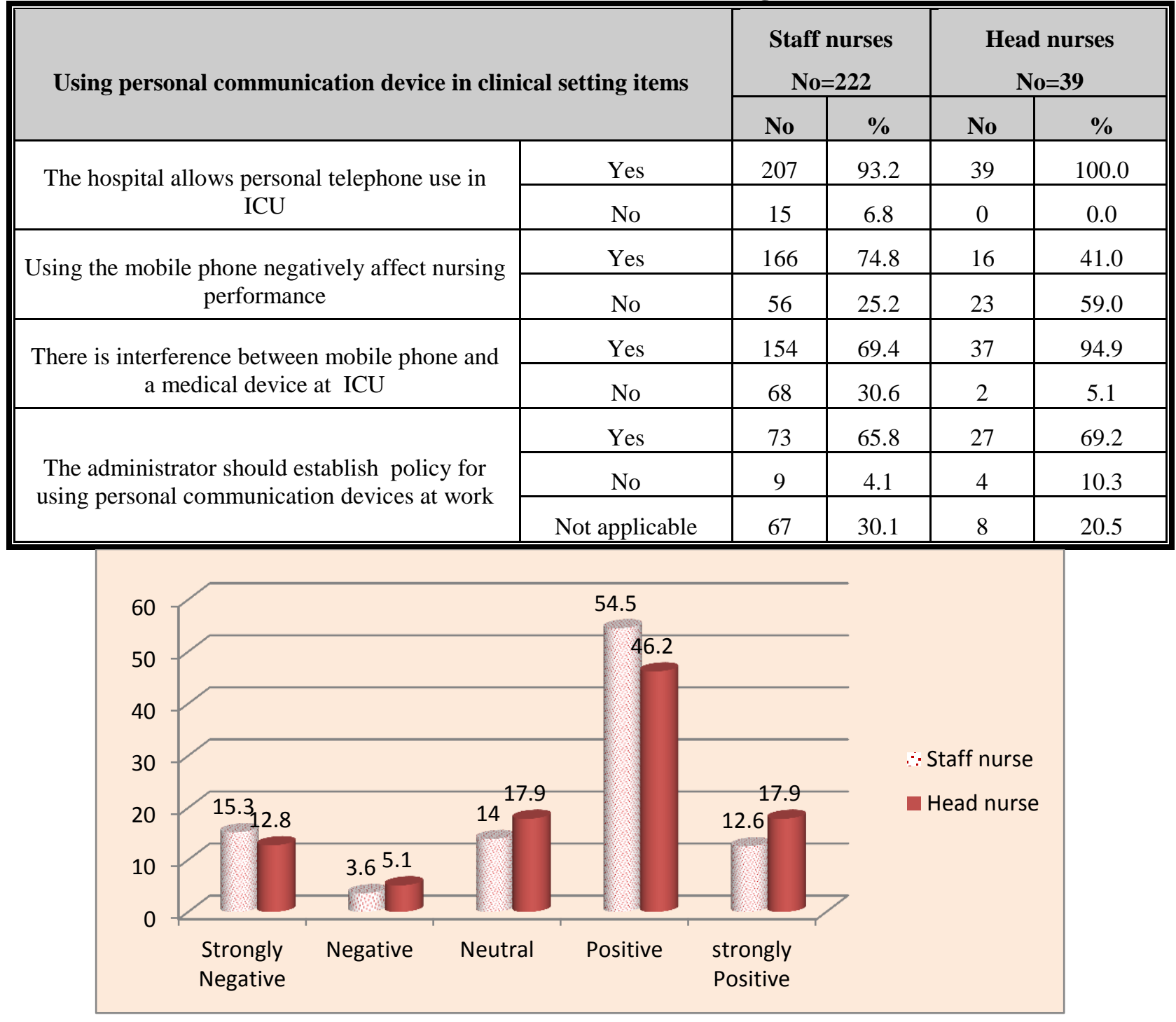

Figure (1): Percentage distribution of nursing staff feeling level toward AMDs 
Nursing staff readiness toward advanced mobile devices utilization in nursing care in critical care units

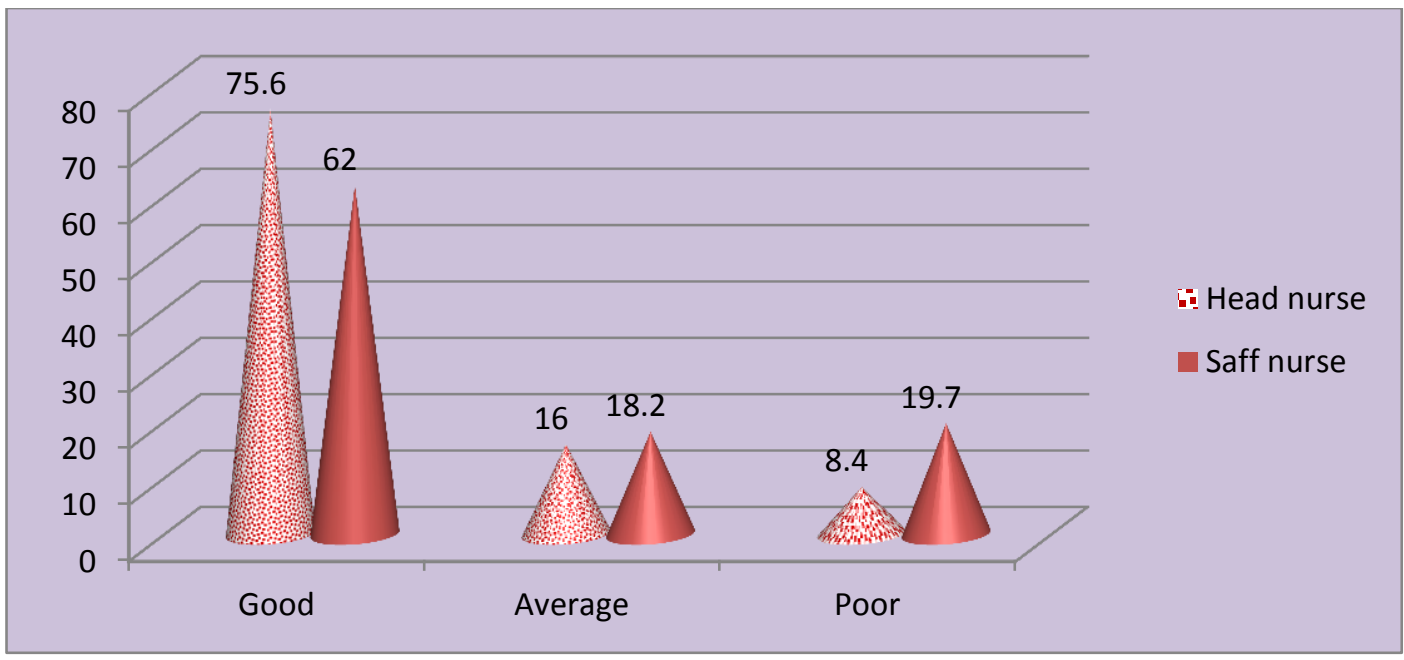

Figure (2): Percentage distribution of nursing staff total knowledge level regarding AMDs utilization in nursing care

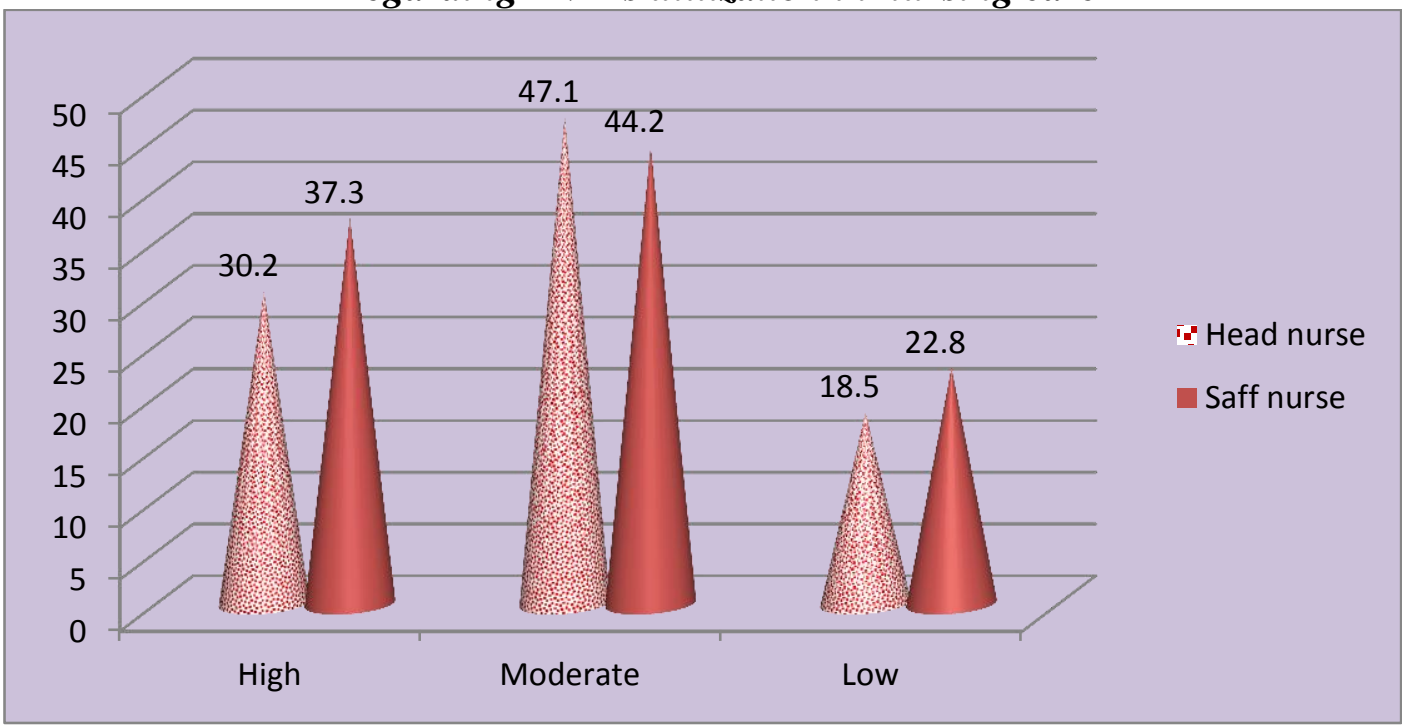

Figure (3):Percentage distribution of nursing staff regarding technology readiness levels

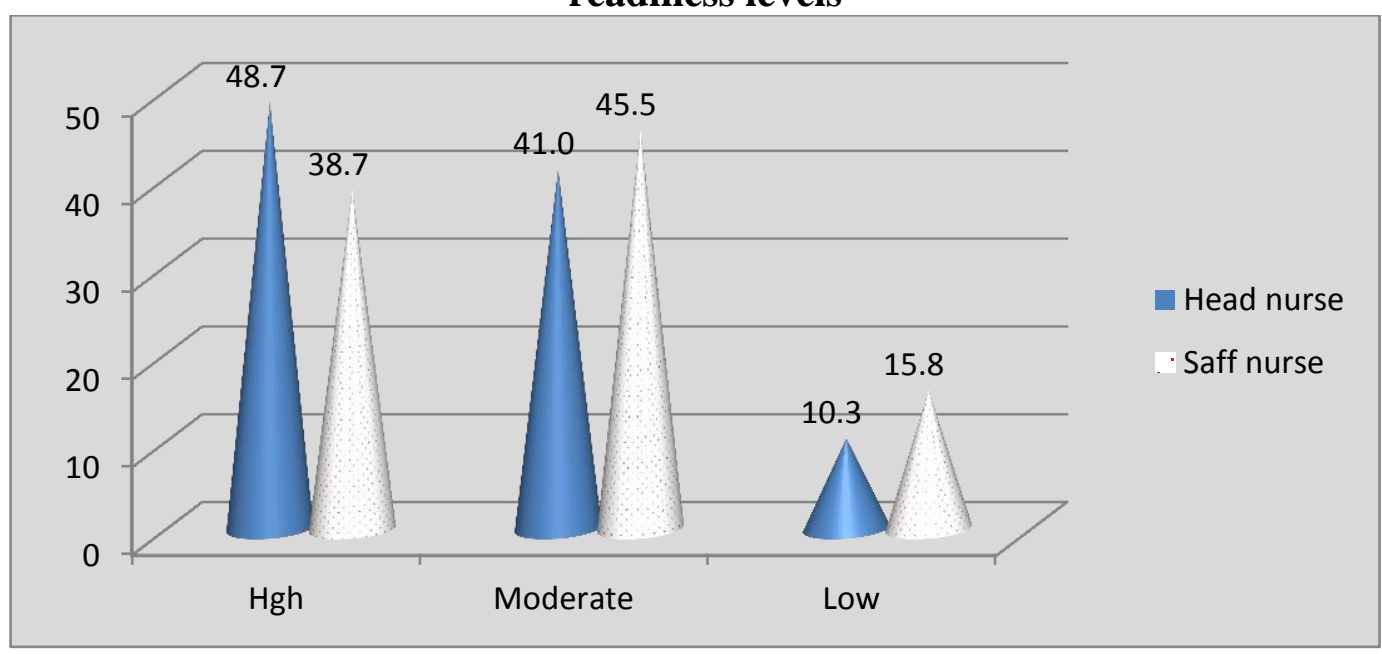

Figure (4): Percentage distribution of nursing staff regarding their total AMDs readiness level 

in critical care units

Table (4): Correlation between nursing staff knowledge regarding AMDs utilization in nursing care and their readiness $N=(261)$

\begin{tabular}{|c|c|c|c|c|}
\hline Item & \multicolumn{2}{|c|}{$\begin{array}{c}\text { Head nurses readiness toward } \\
\text { AMDs }\end{array}$} & \multicolumn{2}{|c|}{$\begin{array}{c}\text { Staff nurses readiness toward } \\
\text { AMDs }\end{array}$} \\
\hline \multirow[t]{2}{*}{ Knowledge regarding AMDS } & $\mathbf{r}$ & p-value & $\mathbf{r}$ & p-value \\
\hline & 0.72 & $0.000 * *$ & 0.54 & $0.001 *$ \\
\hline
\end{tabular}

** Highly statistically significant at $(\mathrm{p} \leq 0.001) *$ Statistically significant at $(\mathbf{p} \leq \mathbf{0 . 0 5})$

\section{Discussion}

The present study aimed to assess nursing staff readiness toward AMDs utilization in nursing care at Benha University hospital: through, assessing nursing staff knowledge regarding AMDs utilization in nursing care, identifying nursing staff readiness towards AMDs utilization in nursing care, comparing between head nurses and staff nurses knowledge and readiness toward AMDs utilization in nursing care and investigating relationship between nursing staff knowledge regarding AMDs utilization in nursing care and their readiness.

Regarding to personal characteristics of the nursing staff, the findings of the present study clearly showed that nearly to three quarters of staff nurses were aged less than 30 years old, the majority of staff nurses were female and the most had diploma in nursing. Also the result showed that more than two thirds of both staff nurses and head nurses had from one to less than 10 years' of experience in hospital.

The result of the present study was consistent with Kivuti and Chepchirchir, (2011) as they found in their study that the majority of nurses were female and Kue et al., (2013) as they found in their study that the majority of staff nurses aged from 20 to 30 years. Moreover, this result was in agreement with Abadel and Saifuddeen, (2017) as they reported in their study that most of the nursing personal had an experience of less than ten years.

In relation to having previous training course in electronic documentation, the results of the present study revealed that the majority of staff nurses didn't have previous training course in electronic documentation .This result was in accordance with Fossum et al., (2011) as they found in their study that the majority of the health workers in these rural facilities had none or very limited training for computer applications. On the other hand, the findings of the present study revealed that more than half of head nurses had age from 31 to 40 years old, the majority were female, and more than two thirds had bachelor of nursing. This result was supported by Godoe and Johansen, (2012) they reported that more than half of head nurses aged between from 31to 40 years and most of them were female. Moreover, Wyatt and Krauskopf, (2012) as they reported in their study that the majority of the respondents either held graduate degrees or were employed by a university or college. In relation to having previous training course in electronic documentation, the findings of the 
present study revealed that more than two thirds of head nurses had previous training course in electronic documentation. This result was in agreement with Lloyd, (2011) who found in his study that most of the respondents had training courses in computer and other computing system applications such as electronic health record. While this result was contradicted with Mitchell, (2009) as he found in his study that the majority of head nurses had low level of previous training in computing systems.

Concerning personal mobile phone, the findings of the present study revealed the majority of both staff nurses and head nurses had advanced mobile phone. This might be related to that the advanced mobile devices provide access to the internet with multiple social media that enable nursing staff to communicate with other departments (laboratories, pharmacy and other different units in the hospital). In the same line O'Connor et al., (2014) reported that the majority of the nursing staff had advanced mobile phones.

In relation to using the mobile phone for work purposes, the findings of the present study revealed that more than two thirds of staff nurses don't use the mobile phone for work purposes. This might be contributed to many factors as they don't have enough time, not experienced enough to use such devices and fear from patient might think that they use mobile phone for other purposes than work. In this respect Smith et al., (2010) they stated that using mobile phone can negatively impact the relationship between doctors and nurses, lead to unprofessional behavior, and be a possible source of infection so that most of the staff nurses don't use it.
On the other hand two thirds of head nurses use the mobile phone for work purposes. This might be due to with AMDs apps; the head nurses can provide care easily, while staying focused on patient interactions. Access the EMR, receive alerts, administer medication and apps on AMDs help reduce friction and increase productivity and overall patient care.

In this respect Lo et al.,(2012) mentioned in their study that smartphones are a very powerful tool for facilitating team working and communication between healthcare providers. Also smartphones can potentially minimize disruptions by allowing prioritization of non-urgent communication so most of the healthcare team prefers to use their mobile phone. Moreover, this result was consistent with Koehler, (2013) and O'Connor et al., (2014) as they found in their studies that the majority of head nurses used their smartphones many times a day for their clinical work.

Concerning using mobile phone in clinical setting, the findings of the present study show that most of staff nurses reported that using of mobile phone negatively affect nursing performance. This might be due to the mobile phone makes it easier for nurses to be interrupted for nonclinical purposes during work time, which decreases nursing staff attentiveness to patient care. This result was inconsistent with Coker, A.,(2011) as they reported that majority of staff nurses didn't believe that their job performance was negatively affected by their personal communication device.

On the other hand more than one half of head nurses reported that using of mobile phone don't negatively affect nursing 
performance. This might be due that AMDs facilitate team working and communication between healthcare and save time and effort. This result was in agreement with $\mathbf{W u}$ et al., (2013) they stated that the majority of the head nurses were strongly disagree that the mobile phones negatively affect their performance.

The results of the present study revealed that more than two thirds of staff nurses reported that there is interference between mobile phone and a medical device at ICU comparing with the majority of head nurses. This may be due to most of nursing staff reported that when they use the mobile phone beside medical equipment they hear sound vibration. In addition to the radiations emitted by the mobile phones can interfere with the functioning of the medical equipment.

In this respect Yeolekar and Sharma, (2004) and Visvanathan et al., (2012) they reported that the nursing personal reported that the mobile phone interfere with medical equipment through radiations emitted by the mobile phones.

In relation to the administrator should establish policy for using personal communication devices at work, the findings of the present study revealed that more than two thirds of both staff nurses and head nurses agreed that the administrator should establish policy for using personal communication devices at work. This might be due to these instructions and polices help to guide nursing staff to use the mobile device at the appropriate time in order to prevent unnecessary interruptions and help them to focus on the patient.

The result of the present study was in accordance with Deborah, (2014) as he found in his study that the majority of the nursing personal said that the administrator should have the policy for using personal communication device at work and reported that the AMDs should never be used for personal calls while working.

As regards feeling toward AMDs, the findings of the present study illustrated that more than two fifth of both staff nurses and head nurses reported that they had positive feeling toward AMDs. This might be due to that AMDs provide them quick access to information and upto-date clinical applications such as medical calculators, drug databases, and disease diagnosis applications. Moreover it facilitates clinical communication such as text messaging, and email messaging. This result was in agreement with Deborah, (2014) reported in his study that most of the study participants had slightly positive feeling and more than one third of them had strongly positive feeling toward AMDs utilization in nursing care.

Concerning knowledge regarding AMDs utilization in nursing care, the findings of the present study indicated that there was a statistically significant difference between staff nurses and head nurses scores regarding total knowledge about AMDs utilization in nursing care. As the highest percent of head nurses reported that they had good knowledge regarding AMDs utilization in nursing care compared to more than two thirds of staff nurses. Moreover results revealed that head nurses had the highest mean score regarding Knowledge about AMDs utilization in nursing care compared to staff nurses.

From the researcher point of view this result could be contributed to many factors such as differences in 

in critical care units

qualifications, level of education and years of experience between head nurses and staff nurses might be one factor. In addition to, the result of the current study revealed that more than two thirds of the head nurses had previous training courses in electronic documentation compared to staff nurses as the majority of them didn't have previous training course in electronic documentation. Engaging head nurses in previous training program increased their knowledge regarding AMDs utilization in nursing care.

The result of the present study was in agreement with Hamed, (2012) as they found in their study that more than two third of respondants had good knowledge regarding smart devices and used it in their daily clinical practice. Moreover Shahi, (2012) reported in his study that the majority of the respondents had average knowledge on E-mail and Internet.

Concerning technology readiness, the findings of the present study indicated that Concerning technology readiness, the findings of the present study indicated that more than two fifth of the head nurses had moderate technology readiness level toward AMDs utilization in nursing care as compared to more than one thirds staff nurses .This may be due to AMDs assist nursing staff in critical care units by providing access to magnetic resonance imaging, ultrasound and computed tomography results from remote laboratories and hospital, reducing the need to carry two separate devices and AMDs had a unique advantage was availability of specially designed mobile applications.

The result of the present study was consistent with Wilson, (2008) reported in his study that most the study subjects were average "technoready". Also they reported that study subjects had positive attitudes toward computer use in nursing. Also in this respect Godoe \& Johansen, (2012) mentioned in their study that the personality dimensions of technology readiness index influence technology acceptance and usage. Optimism and innovativeness were significantly affected perceived usefulness and perceived ease of use.

In the same line Brett et al., (2012) found in their study that the participants feel that they were technology ready and Kuo et al., (2013) reported in their study that nurses have technology readiness and they are optimistic, innovative, secure but uncomfortable about technology. Moreover in this respect Chen et al., (2013) mentioned in their study that individuals with higher technology readiness frequently had higher satisfaction, trust, and intention on using eappointment system and technology readiness was a major determinant of electronic system success such as (cell phones, I pads, laptop).

Regarding readiness toward AMDs utilization in nursing care, the findings of the present study clearly showed that nearly half of head nurses had high readiness level compared to more than one third of staff nurses. In addition to the results revealed that that head nurses had the highest mean score regarding readiness toward AMDs utilization in nursing care compared to staff nurses.

From the researcher point of view this result could be interpreted in the light of the study subject responses as the highest percent of head nurses had good knowledge score regarding AMDs utilization in nursing care compared to more than two thirds of 
staff nurses, had required technical skills to use AMDs more than staff nurses. Moreover head nurses reported that using AMDs will provide access to information and will benefit them in nursing care more than staff nurses and thus enhance their readiness in terms of optimism, innovativeness, and perceived usefulness, motivation and attitude toward AMDs utilization in nursing care.

In addition to, beside head nurses roles in planning, organizing, and directing health services provided by staff nurses in nursing units, head nurses have to mentor, facilitate and evaluate junior members. Sometimes, head nurses need to coordinate staff nurses or communicate with physicians within or between units. To fulfill these expectations, communication is one of the most important competencies that head nurses must possess .Therefore, head nurses seek to improve the communication skill. AMDs facilitate communication among providers and help them to complete their duties in sufficient manner. On the other hand staff nurses role is differ from that of head nurse. As they provide direct patient care and bedside care such as (bed making, changing of bed sheets, mouth care, back care, bed bathing, hair wash, changing of position) and they fulfill all basic needs (hygienic need and nutritional need) of the patients.

In the same line Kipturgo et al., (2014) reported in their study that nurses had a favorable and positive attitude towards computerization and other computing system and tend to become ready to use computing systems in clinical practice. Also Wesam, et al., (2016) reported in their study that the nurse's overall readiness is considered at a high level.

The findings of the present study revealed that there were statistically significant positive correlation between nursing staff knowledge and readiness regarding AMDs. This might be due to nursing staff with enough knowledge about AMDs tending to become more ready to use it in nursing care. Moreover increased nursing staff knowledge regarding concept, uses advantages and disadvantages of AMDs help them to be more ready to use these new devices.

The result of the present study was matched with Koolaee et al., (2015) as they found in their study that readiness of healthcare providers is related to their computer skills and knowledge about AMDs application such as HER. On the other hand this result was inconsistent with Jebraeily et al., (2010) as they reported that nurses who have high knowledge AMDs application have a low attitude and readiness toward it.

\section{Recommendations}

In the light of the findings obtained from the present study, the following points are recommended:

\section{For hospital administration:}

- The hospital should take the necessary steps to develop proper ICT infrastructure required for AMDs utilization in nursing care.

- Nursing administrators must be encouraged to assess the impact of pre implementation information systems on nursing staff, as well as the staff's degree of willingness to use them.

- The hospital management should consider generational differences in interest and competence of the nursing staff. 
- Hospital administration must provide ICT support through increasing nursing staff awareness, and a drive to adopt new system or functions.

- The informatics education programs should be incorporated into orientation program for new hiring and into a continuing education program schedule to enhance nurses support, confidence as well as comfort at AMDs usage.

- Hospital administration play an important role to encourage nurses to utilize health information technology to deliver evidence based care, support communication between health care providers and with patient and remotely monitor patient.

- Hospital administration should have rapid response system to deal with a wide range of clinical technical problems.

\section{For nursing education}

- Academic nurse leaders should incorporate nursing informatics into nursing curriculum to improve practice, address unwarranted variations and enhance outcome.

- Nurse educators are called to utilize power of technology to work toward the vision of continuously learning health system.

\section{For further research:}

- Assess perceived usefulness of AMDs utilization in nursing care among nursing staff and stakeholders.

- Investigating the perceptions of AMDs utilization and barriers to its uptake in both male and female nursing staff at all stages in their careers.
- Assess reasons for nursing staff resistance to adopt AMDs utilization in nursing care.

\section{References:}

Abelson, J, S., Kaufman, E., Peters, A, Charlson, M. and Yeo, $\mathrm{H}$ (2017): Barriers and benefits to using mobile health technology after operation: A qualitative Study: Presented at the Academic Surgical Congress in Las Vegas, NV, 162(3): 605-611.

Aldhafeeri, M, F and Khan, H, B (2016): Teachers' and Students' Views on ELearning Readiness in Kuwait's Secondary Public Schools; Journal of Educational Technology Systems: First Published

Abadel, M, H and Saifuddeen A. A. (2017): Study of Knowledge, Attitude and Preferences of Primary Health Care Physicians in Saudi Arabia Regarding the Use of Medical Software Applications on their Smartphones. Annals of International Medical and Dental Research: 3: (2)

Bala, A (2017): How Technology Is Changing Nursing: The Impact of Telehealth. Available at https://www.medscape.com

Beauregard, P., Arnaert, A. and Ponzoni, N. (2017): Nursing students' perceptions of using smartphones in the community practicum: A qualitative study: Nurse Education Today , 53 (3): 1-6.

Choi, M., Leem H. and Park, J,H. (2018): Effects of using mobile device-based academic electronic medical records for clinical practicum by undergraduate nursing students: A quasi-experimental 

in critical care units

study: Nurse Education Today, 61(13): 112-119.

Chen, S. C., Liu, M, L. and Lin, C, P. (2013): Integrating technology readiness into the expectation-confirmation model: an empirical study of mobile services: Cyberpsychology, Behavior, and Social Networking, 16 (8):604-612.

Cipriano P, F (2013): Nursing, Technology, and Information Systems. Am Nurse Today; 8(11); 109-114 Available at :URL:

https://americannursetoday.c om/

Coker , A (2011): Freedom to Surf: the positive effect of the internet leisure browsing: New technology ,Work and Employement :26(3):238-241

Cummings, E., Shin, E, H., Mather, C. and Hovenga, E. (2016): Embedding nursing informatics education into an Australian undergraduate nursing degree: Studies of Health Technology and Informatics, 225-329.

Deborah, L(2014): registered nurses, use of personal communication device in hospitals: Dissertation Committee :guangxiang Zang.

Fossum, M., Ehnfors, M., Fruhling , A. and Ehrenberg, A. (2011): An evaluation of the usability of a computerized decision support system for nursing homes. Applied Clinical Informatics, 2(1): 420-436

George, P, T., DeCristofaro, C., Murphy, F, P. and Sims, A. (2017): Student Perceptions and Acceptance of Mobile Technology in an Undergraduate Nursing
Program: Healthcare (Basel), 5(3): 35-39.

Godoe, P. \& Johansen, T.S., (2012): Understanding adoption of new technologies: Technology readiness and technology acceptance as an integrated concept. Journal of European Psychology Students:3(1);3852.

Jebraeily, M., Ahmadi, M., Hajavi, A., Gohari, M., Sedghi, J, M. and Zareh, Z. (2010): Electronic Health Records: Personnel Readiness Assessment: Journal of health informatics, 13(39):17-24.

Jelec, k., sukalic, S., friganovic, A. and vitae, S. (2016): Nursing and implementation of modern technology: signa vita journal in intensive care and emergency medicine: 12(1): 23-27.

Johansson, P. \& Pettrson, G., (2014):Using advanced mobile devices in nursing practice the view of nurse and nursing student :Health Informatics Journal, 20(3): 220-321.

Keegan, R, D., Oliver, C., Stanfill, T, J.,Stevens K, V., Brown, G,

R., Ebinger, M. and Gay, J, M. (2016): Use of a mobile device simulation as a pre class active learning exercise: Journal of Nursing Education, 55 (1): 56-5.

Kipturgo, M, K., Kivuti-Bitok, L, W., Karani, A, K. and Muiva, M, M. (2014): Attitudes of nursing staff towards computerization: a case of two hospitals in Nairobi, Kenya: BMC Medical Informatics and decision making, 14(3): 35 .

Kivuti, L. and Chepchirchir, A. (2011): Computerization readiness. Online Journal of 
Nursing Informatics (OJNI), 15, (1): 178 Available at http://oini.org/issues/?

Koehler, N., Vujovic, O. and McMenamin, C. (2013): Healthcare professionals' use of mobile phones and the internet in clinical practice: Journal of mobile technology in medicine, 2 (1):3-13.

Koolaee, H, M., Safdari, R. and Bouraghi, H. (2015): Nurses Readiness and Electronic Health Records: journal of the Society for Medical Informatics, 23(2): 105-107.

Kue, K, M., Liu, C, F. and Ma, C. (2013): technology readiness on the acceptance of mobile electronic medical record systems: BMC Medical Informatics and Decision Making:1(1):13-88.

Lioyd, S, B. (2011): What are the main determinants for attitude to use mobile phone application: FHR Lim A Po Institute 15(2):1-15. Maastricht School of Management.

Lo, V., Wu, R, C., Morra, D., Lee, L. and Reeves, S. (2012): The use of smartphones in general and internal medicine units: a boon or a bane to the promotion of inter professional collaboration?: Journal of International professional Care, 26(6):276-82.

Mann, E, G., Medves, J. and Vandenkerkhof, E, G. (2015): Accessing best practice resources using mobile technology in an undergraduate nursing program: CIN: Computers, Informatics,

Nursing, 33 (3): 122-128.
Martyn, A., Larkin, K., Sander, T., Yuginovich, T. and JamiesonProctor, R. (2014): Distance and devices - Potential barriers to use of wireless handheld devices: Nurse Education Today, 34: 457-461.

Mather C,A, \& Cummings E,(2015): $\quad$ Empowering learners: using a triad model to promote eHealth literacy and transform learning at point of care: Knowl Manag ELearn: Int J; 7(4):629-45.

Mather CA \& Cummings E(2015): Unveiling the mobile learning paradox:Stud Health Technol Inform; 2(18) :126-31.

Mechael, P, N., Batavia, H., Kaonga, N., Searle, S. and Kwan A, (2017): Barriers and gaps affecting $\mathrm{m}$ health in low and middle income countries: Policy White Paper: Center for Global Health and Economic Development, Earth Institute, Columbia University.

Muhanna, W., \& Abu-Al-Sha'r, A. (2009): University student attitude toward cell phone learning : Faculty of Educational Science ( 1Al-alBayt University, 2Al-al-Bayt University ) Available aSciencesawatifabualshar@ya hoo.com, retrived at 11 , janurary,2017,11:00 pm.

O'Connor, P., Byrne, D., Butt, M., Offiah, G., Lydon, S., Mc Inerney, K., Stewart, B. and Kerin, M，J. (2014): Interns and their smartphones: use for clinical practice, Postgraduate Medical Journal, 90, 75-79.

Sewell JP (2016): Informatics and nursing: opportunities and challenges. 5th ed. Philedelphia: Lippincott Williams and Wilkins 
Shahi M.,(2012): Knowledge, attitude and application of computer by Bachelor Level Nursing students: journal of Institute of Medicine; 34 Available at www.jiom.com.np.

Smith, T., Darling, E. and Searles, B. (2010): Survey on cell phone use while performing cardiopulmonary bypass: Perfusion, 26(3):375-80.

Visvanathan, A., Gibb, A, P. and Brady, R, R. (2012): Increasing clinical presence of mobile communication technology: avoiding the pitfalls: Telemedicne Journal of Electronic Health ,17: 65661.

Wesam a.T. Fargaly, M.Sc. and Eglal A. abd el-wahab (2016): Nurses' Readiness for Using the Electronic Information System at A Selected Hospital in Giza Governorate: Med. J. Cairo Univ : 84( 3):pp 221227

Wyatt, T. \& Krauskopf, P. (2012): E-health and Nursing: Using Smartphones to Enhance Nursing Practice. Online Journal of Nursing Informatics (OJNI), 16 (2); 1706
Wu, R. C., Tzanetos, K., Morra, D., Quan, S., Lo, V., \& Wong, B. M. (2013): Educational impact of using smart phones for clinical communication on general medicine: More global, less local: Journal of Hospital Medicine: 8(7): 365372.

Wilson, R, (2008): Technology readiness, attitude towards computers and computer literacy among first year nursing students: a Canadian perspective: Theses and dissertations. Paper 900: Ryerson University: available at Digital Commons @ Ryerson

Yeolekar, M, E and Sharma, A (2004): Use of mobile phones in ICU - Why not ban? The Journal of the Association of Physicians of India: JAPI.: 52. Available at: www.japi.org

Zayim, N and Ozel, D (2015): Factors affecting nursing students' readiness and perceptions toward the use of mobile technologies for learning: CIN: Computers, Informatics, Nursing; 33 (10); 456-464 